\title{
On the Relative Importance of Corporate Working Capital Determinants: Findings from the EU Countries
}

\author{
Julia Koralun-Bereźnicka ${ }^{1}$
}

ABSTRACT

\begin{abstract}
The corporate finance literature traditionally abounds in both theoretical discussion and empirical research concerning financing and long-term investment decisions. Managing short-term resources appears to be a much less remarkable issue, despite this resource's significant share of a firm's balance sheet and the time and effort required to manage the current assets and liabilities. This article provides insights into the relative importance of the selected working capital determinants from the European Union perspective. The determinants considered in the study include both external and internal factors, specifically the country in which a company operates, its industrial classification and the firm size. Using more than 10,000 aggregated observations from a sample of firms from 13 industries, 9 countries and 3 group sizes, covering the period 2000-2009, the findings provide evidence that corporate working capital is most affected by country-specific factors, followed by industrial factors and firm size.
\end{abstract}

KEY WORDS: $\quad$ working capital; country factors; industry factors; firm size; EU

JEL Classification: G30

${ }^{1}$ University of Gdańsk - Faculty of Management, Poland

\begin{abstract}
Introduction
The problem of working capital (WC) determinants is crucial from the managers' perspective because they invest a significant amount of time and effort in searching for an optimal balance between liquidity and profitability and, consequently, between risk and return. WC management, which involves monitoring each component and minimizing deviations from the target level, is a complicated and time-consuming process (Appuhami, 2008; Kim \& Srinivasan, 1991; Lam-
\end{abstract}

Correspondence concerning this article should be addressed to: Julia Koralun-Bereźnicka University of Gdańsk - Faculty of Management, Armii Krajowej 101, 81-824 Sopot, Poland. T: +48 58 5231475.E-mail: jkb@wzr.ug.edu.pl berson, 1995). The deficiencies in knowledge regarding WC determinants may lead to the insolvency and bankruptcy of firms whose financial managers fail to effectively plan and control current assets and liabilities (Rafuse, 1996). Despite its importance for corporate health (Filbeck \& Krueger, 2005), there is insufficient empirical evidence regarding the determinants of WC management, considering the combined effect of the main components: inventory, accounts receivable and accounts payable (Palombini \& Nakamura, 2011).

In contrast to the richness of both theoretical and empirical studies on capital structure and its nearly countless determinants (Rajan \& Zingales, 1995), the theories of WC are much less developed; in addition, as Palombini and Nakamura (2011) conclude from an overview of corporate finance literature, 
there are no robust and widely accepted theories explaining the WC management. According to Saarani and Shahadan (2012), the nearest relevant theory is the Pecking Order Theory of debt developed by Myers and Majluf (1984); however, this theory is meant to explain the internal and external factors affecting corporate financial leverage and not the use of short-term assets and liabilities.

The discussion regarding the factors that affect WC policy is complex. The majority of previous studies on WC management aimed at exploring its relation with corporate profitability by evaluating the influence of WC strategies on the value created for shareholders. Despite its importance for managers, there is little empirical research that attempts to prioritize WC determinants according to their significance. The objective of this study is to establish the hierarchy of the three factors that are commonly believed to impact WC, i.e., the country- and industryspecific factors and the firm size, and thus contribute to the corporate finance knowledge of short-term decisions. The research is based on a sample of firms of all sizes from 13 industries and 9 EU countries, and it covers the period 2000-2009.

Because the efficiency of WC management affects the profitability and liquidity of the firm (Deloof, 2003) and, as a result, constitutes a fundamental part of the overall corporate strategy to create value for shareholders (Nazir \& Afza, 2009), knowing how these factors are prioritized into a hierarchy may provide some useful practical implications for managers. The WC level is an important factor that influences the operational risk of a company. Therefore, if these factors were primarily industry factors that are responsible for WC diversification, expanding corporate activities by exploiting other technologies would be desirable from the perspective of operational risk mitigation. However, if the country nature were the main determinant of WC requirements, an international expansion of corporate activity would be most advisable. Similarly, finding that the WC requirements are primarily sizedependent would provide useful information for both managers and (or) investors regarding the cross-size diversification of corporate risk.

This study contributes to the corporate finance literature in several ways. First, it extends the empirical work on WC determinants by considering a number of European countries that are analyzed in a comparative manner. Although the topic has previously been explored on multiple occasions in other markets, the studies usually consist of single economies and not a complex, integrated area. Second, due to the easily accessible data, the majority of studies in the field focus on large public companies, whereas this study includes private companies of various sizes, including SMEs, which usually form the core of most economies. Third, many studies adopt an approach that verifies the statistical significance of potential WC determinants. Although such verification is useful and informative, this study goes beyond that scheme by attempting to prioritize the three determinants according to their relevance. Finally, the methodology used for this purpose is intuitively appealing and communicative because the classification process is one of the most common, simple and effective methodologies, thus enabling recognition of the reality.

\section{Country, industry and size as working capital determinants \\ - review of the literature}

Corporate decisions concerning WC can be affected by a number of factors of both external and internal character. One such factor is the impact of corporate financing decisions. In accordance with the Pecking Order Theory of capital structure in the context of the WC policy, companies with a higher financial leverage choose a more aggressive WC strategy, which includes tightening credit conditions for customers and inventory reduction, to provide internal financing and avoid issuing debt and equity. The negative relation between the firm's debt level and its WC is commonly noted in the literature (Chiou, Cheng \& Wu, 2006; Nazir \& Afza, 2008; Palombini \& Nakamura, 2011).

The country specificity is a widely recognized and accepted factor for differentiating capital structure across firms from different countries. There are a number of country-specific factors that can influence corporate financing strategy (Bancel \& Mittoo, 2004; Booth et al., 2001; Claessens, Djankov \& Nenova, 2001; Demirgüç-Kunt \& Maksimovic, 1999; Jõeveer, 2013), including political aspects, economic growth, capital market development and, in particular, the legal and institutional environments explored by La Porta et al. (1997). 

fects was reported by Hill, Kelly and Highfield (2010), whose sample consisted of 20,710 firm-year observations for 3,343 companies from 1996-2006 from the COMPUSTAT database.

Similar to the industry effect in WC management, the effect of size has also received attention of many authors. These authors are often the same who analyze industrial factors, and this effect is noted in their research papers. Most find firm size to be significant in terms of its impact on WC.

The direct correlation between the $\mathrm{WC}$ requirement and size is supported by Petersen and Rajan (1997), who claimed that firms may be financed by their suppliers rather than by financial institutions. The authors focused on small firms whose access to capital markets may be limited and found evidence suggesting that firms use more trade credit when credit from financial institutions is unavailable. Moreover, firms with better access to credit offer more trade credit.

Padachi (2006) also found WC management of particular importance to the small business. According to the author, due to the limited access to the long-term capital markets, these firms tend to rely more on owner financing, trade credit and short-term bank loans to finance their investment in cash, accounts receivable and inventory (Chittenden, Poutziouris \& Michaelas, 1998; Saccurato, 1994).

The efficiency of a company's WC management was also found to be significantly influenced by firm size in a previous study by Kieschnick et al. (2006), although the direction of the effect is not obvious. The authors suggested two alternatives: either larger firms may require larger investments in WC because of their larger sales levels, or larger firms may be able to use their size to build better relationships with suppliers that are necessary for reductions in WC investments. Supply chain management practices require a great deal of coordination between companies and are usually easier for a larger firm to implement than they are for a smaller one. Thus, firm size is likely to influence the efficiency of a firm's WC management; in addition, the empirical evidence shows a positive correlation between the inefficiency of a firm's WC management and a firm's total assets used as a proxy for its size.

The recent findings by Hill et al. (2010) show that the WC requirement varies directly with lagged firm size and that this association is significant. Similar to other researchers, the authors interpreted the relation as size represents capital market access. Thus, smaller firms are more limited in their choices for financing a positive WC requirement because they are less able to issue commercial papers or obtain lines of credit.

The same reasoning is followed by Opler et al. (1999), who indicated, in their research examining corporate cash holdings, that cash and size are inversely related because large firms have less need to hold cash as they have better access to short-term debt markets. Firms that have the greatest access to the capital markets, i.e., large firms and those with high credit ratings, tend to hold lower ratios of cash to total non-cash assets. These results are consistent with the view that firms hold liquid assets to ensure that they will be able to invest when cash flow is insufficient, relative to investment, and when outside funds are too expensive. Consequently, smaller firms will monitor their operating WC strategies more closely because they have fewer alternatives available to finance the WC relative to larger firms.

Firm size was also one of the factors explored in the study by Chiou et al. (2006) in terms of their impact on WC management of the firms listed on the Taiwan Stock Exchange. The study is one of the few whose results did not provide evidence for the influence of the firm size on WC management. Firm size was also found to be insignificant by Nazir and Afza (2008), who explored the factors that determine the requirements of WC management with reference to Pakistani listed firms.

As is clear from the above review, the industrial influences and the effect of firm size were the subject of multiple studies aiming to evaluate their impact on corporate WC. However, the reported results do not provide information on the relative importance of the factors considered because the majority of research is limited solely to identifying the significance of a given factor, possibly with the direction of its impact on WC. The authors of the discussed research papers did not attempt to prioritize the analyzed factors in terms of the importance of their impact on WC management. The results generally focus solely on determining the statistical significance of each variable in the context of the WC or its components.

The lack of inference regarding the relative importance of the effect of industry, country and size makes 
Table 1. Economic sectors covered by the analysis

\begin{tabular}{|c|c|c|}
\hline NACE & Section & Symbol \\
\hline A & Agriculture, forestry and fishing & $A G R$ \\
\hline B & Mining and quarrying & MIN \\
\hline C & Manufacturing & MNF \\
\hline D & Electricity, gas, stream and air conditioning supply & ELE \\
\hline E & Water supply; sewerage, waste management and remediation activities & WAT \\
\hline F & Construction & CST \\
\hline G & Wholesale and retail trade; repair of motor vehicles and motorcycles & TRD \\
\hline $\mathrm{H}$ & Transport and storage & TRS \\
\hline I & Accommodation and food service activities & HOT \\
\hline J & Information and communication & INF \\
\hline L & Real estate activities & RLE \\
\hline M & Professional, scientific and technical activities & PRF \\
\hline $\mathrm{N}$ & Administrative and support service activities & ADM \\
\hline
\end{tabular}

Note: The NACE column represents the official symbol of each section in the classification system, whereas the three-lettered expressions in the last column are the author's symbols used for clarity throughout the tables. Source: Statistical Classification of Economic Activities in the European Community, Rev. 2 (2008)

it useful to expand the research to fill this gap and establish the hierarchy of the factors in question.

\section{Hypotheses, data and methodology}

The main objective of the study is to evaluate the impact of the country effect, the industry effect and the size effect in the corporate WC ratios in selected EU countries. The intended result of the analysis is, therefore, to determine which of these factors has the greatest influence on WC policy. As a result, the study should provide a hierarchy of the factors according to the strength of their impact on the WC. To solve this research problem, which can be defined as the assessment of the relative importance of the three effects, the analysis is conducted in three sections: across countries, across industries and across size groups.

The hypotheses to be verified matches pairs of factors, which are subject to a comparative analysis in terms of their impact on the WC. The pairs are as follows:

- country-specific and industry-specific factors,

- industry-specific and size-specific factors, and

- country-specific and size-specific factors.

For example, the prevalence of the country factors over the industrial factors would mean that companies from different industries in the same country are characterized by a larger mutual similarity in terms of WC than companies in the same industry but from different countries. The prevalence of the industrial factors over the factors related to the size of the company would be associated with a greater cross-industry diversity of corporate WC than across different size groups. However, a firmly uniform diversity of the WC ratios in the three cross-sections would make it difficult to identify the dominant factor accurately and prioritize the others. 
The empirical analysis includes companies of three group sizes: small (with a net turnover of less than EUR 10 million), medium (with a turnover of 10 million euros to 50 million euros) and large (with a turnover of over EUR 50 million) in thirteen industries according to the NACE classification (Nomenclature Statistique des Activités économiques dans la Communauté Européenne) and in the nine European Union countries available in the Banque de France (2012) database: Austria, Belgium, Germany, Spain, France, Italy, the Netherlands, Poland and Portugal. Table 1 shows the industries covered by the study and the three-letter symbols assigned to each sector used in the following part of the paper.

According to the Banque de France (2012) database user guide, the samples for different countries represent a relatively large coverage. However, there are certain limitations of disclosure because the statistics for a specific year, size and sector are only published if they refer to a certain number of companies (depending on countries) and have a sufficient coverage rate.

The database used for this study requires comment in terms of the heterogeneity of the samples in different countries. The Banque de France (2012) results are based on variable samples in different years. The data are representative because they result from an exhaustive or a proper statistical sampling method.

The compilation methods used by the national authorities to produce the time series are different. They directly depend on the degree of exhaustiveness or representativeness of the statistical base material that is available for the national financial statement statistics.

Those countries that have an exhaustive survey (such as Belgium and Portugal) can provide figures that are not affected by changes in the composition of the sample population; therefore, these figures can directly be compiled as time-series. These results are representative of the entire population of firms included in the statistical survey, and the observed changes in the ratios can only be interpreted as a result of economic changes. In other countries, however, the selected companies do not represent a complete survey and may not be a statistically representative sample.

Furthermore, the composition of the sample population changes every year, and the compilation of time series from such samples can raise problems of analysis because the changes in the results over time do not necessarily reflect representative economically in- duced evolutions of the monitored variables or ratios; they also reflect fluctuations in the sample population. This statistical error originating from differences in the sample population, called sample composition bias, primarily impacts the weighted average calculations that were used in this study.

The Banque de France (2012) database enables the international and cross-industry comparison of ratios and their comparison across different size groups because the available data are harmonized to the greatest possible extent and aggregated. On the one hand, this aggregation facilitates the detection of certain regularities. On the other hand, it results in the loss of significant amounts of information and generates inevitable errors as a consequence of the data generalization. Inference based on research conducted using the database can also be prone to errors resulting from the random sampling of companies in each country covered by the database. Although the coverage rate of the population is usually quite high (more than $70 \%$ on average), it is much lower for some countries and is even unknown for others, such as Poland.

The harmonized and aggregated data from the annual reports of non-financial firms were used to calculate the WC ratios for groups of companies in each country, sector, size group and each year of the tenyear study period covering the years 2000-2009.

To perform a complete analysis of the corporate WC structure, it is desirable to examine the basic WC ratio and the various compounds of the WC. Thus, considering the data availability, the analysis involves four financial ratios illustrating the relation of inventories, trade accounts receivable, trade accounts payable and operating WC to net turnover. The details of the diagnostic variables are shown in Table 2.

In summary, the subject of the study is formed by the groups of companies of different sizes, from different industries in different countries and years. The WC, measured using the financial ratio, is the object of the analysis. Thus, the study includes four financial ratios for the three size groups of enterprises in thirteen sectors and nine countries for ten years; after accounting for the missing data, the study includes 10,071 observations (data items). The source of data is the Banque de France (2012) (Bank for the Accounts of Companies Harmonised - European Sectoral references Database). 
Table 2. Working capital ratios used in the analysis

\begin{tabular}{lcc}
\hline Ratio structure & Symbol & Ratio number in the database \\
\hline Inventories / Net turnover & INV & R17 \\
Trade accounts receivable / Net turnover & TAR 18 \\
Trade accounts payable / Net turnover & TAP & R19 \\
Operating working capital / Net turnover & OWC & R20 \\
\hline
\end{tabular}

Note: Source: Banque de France (2012)

Table 3. Descriptive statistics for all years, countries, industries and size groups

\begin{tabular}{ccccccc}
\hline Ratio & $\mathbf{N}$ & Mean value & Median & Minimum value & Maximum value & Standard deviation \\
\hline INV & 2981 & 0.128 & 0.066 & 0.000 & 4.345 & 0.258 \\
TAR & 2708 & 0.234 & 0.199 & 0.024 & 1.890 & 0.170 \\
TAP & 2191 & 0.183 & 0.167 & 0.000 & 1.499 & 0.106 \\
OWC & 2191 & 0.197 & 0.139 & -1.189 & 4.131 & 0.309 \\
\hline
\end{tabular}

Note: Source: author's calculations based on Banque de France (2012)

The ratios used in the analysis are continuous variables, which is why they may be analyzed using descriptive statistics, including the mean value, minimum, maximum and standard deviation. The descriptive statistics for the total sample are presented in Table 3.

It is also relevant and informative to examine the basic statistics of the ratios by categories, i.e., by year, and particularly, by country, industry and company size, as shown in Table 4. In addition to the average level of ratios for each category, the table indicates major data gaps.

The choice of the research methodology is, to a large extent, conditioned by the nature of the data, which is a relatively large collection of objects (industries, size groups, countries and years) that are characterized by a few diagnostic variables. The data are four-dimensional because there is a time series for each object in the three cross-sections (countries, industries, size groups), which would normally require the application of panel data modelling to detect the hypothesized effects. However, due to the previously noted lack of complete cross-time comparability of data for some countries, the panel data analysis, which would otherwise be an effective way of discovering patterns within the population, does not appear to be an ideal method of data exploration in this case.

Therefore, an alternative method is multivariate analysis, which is a natural tool for simultaneously simplifying the structure of the data and identifying the most important regularities. The review of the existing research suggests that multivariate classification often provides an effective solution to similar research problems (Boillat, de Skowronsky \& Tuchschmid, 2002; Cinca, Molinero \& Larraz, 2005; Gupta \& Huefner, 1972; Helg et al., 1995; Sell, 2005).

The initial phase of the empirical research is the analysis of the descriptive statistics of the WC ratios across countries, industries, size groups and years. It is aimed at the preliminary recognition of the WC diversity in the above cross-sections and at detecting basic regularities within the population. 
Table 4. Mean values of working capital ratios by year, country, industry and size group

\begin{tabular}{|c|c|c|c|c|c|c|c|c|}
\hline \multirow[t]{2}{*}{ Year, country, industry, size } & \multicolumn{2}{|c|}{ INV } & \multicolumn{2}{|c|}{ TAR } & \multicolumn{2}{|c|}{ TAP } & \multicolumn{2}{|c|}{ OWC } \\
\hline & $\mu$ & $\delta$ & $\mu$ & $\delta$ & $\mu$ & $\delta$ & $\mu$ & $\delta$ \\
\hline 2000 & 0.122 & 0.150 & 0.242 & 0.162 & 0.183 & 0.086 & 0.179 & 0.177 \\
\hline 2001 & 0.122 & 0.187 & 0.242 & 0.162 & 0.184 & 0.089 & 0.187 & 0.211 \\
\hline 2002 & 0.127 & 0.209 & 0.244 & 0.168 & 0.181 & 0.088 & 0.200 & 0.253 \\
\hline 2003 & 0.129 & 0.261 & 0.242 & 0.172 & 0.183 & 0.085 & 0.200 & 0.300 \\
\hline 2004 & 0.124 & 0.249 & 0.236 & 0.171 & 0.182 & 0.089 & 0.191 & 0.287 \\
\hline 2005 & 0.120 & 0.236 & 0.221 & 0.143 & 0.189 & 0.125 & 0.185 & 0.285 \\
\hline 2006 & 0.116 & 0.227 & 0.225 & 0.148 & 0.187 & 0.115 & 0.190 & 0.276 \\
\hline 2007 & 0.127 & 0.262 & 0.230 & 0.167 & 0.191 & 0.100 & 0.206 & 0.302 \\
\hline 2008 & 0.144 & 0.325 & 0.230 & 0.200 & 0.191 & 0.137 & 0.222 & 0.426 \\
\hline 2009 & 0.149 & 0.360 & 0.231 & 0.196 & 0.160 & 0.119 & 0.203 & 0.428 \\
\hline AT & 0.100 & 0.081 & 0.116 & 0.041 & 0.097 & 0.106 & 0.086 & 0.130 \\
\hline $\mathrm{BE}$ & 0.099 & 0.096 & 0.295 & 0.264 & 0.191 & 0.119 & 0.172 & 0.262 \\
\hline DE & 0.119 & 0.131 & 0.094 & 0.036 & & . & . & 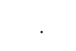 \\
\hline ES & 0.207 & 0.379 & 0.282 & 0.161 & 0.201 & 0.111 & 0.260 & 0.396 \\
\hline $\mathrm{FR}$ & 0.091 & 0.085 & 0.214 & 0.078 & 0.156 & 0.045 & 0.125 & 0.085 \\
\hline IT & 0.121 & 0.139 & 0.402 & 0.163 & 0.272 & 0.074 & 0.231 & 0.173 \\
\hline $\mathrm{NL}$ & 0.057 & 0.040 & & . & & . & $\cdot$ & . \\
\hline$P L$ & 0.071 & 0.065 & 0.142 & 0.050 & & . & . & · \\
\hline PT & 0.240 & 0.552 & 0.244 & 0.106 & 0.174 & 0.072 & 0.301 & 0.506 \\
\hline$A G R$ & 0.225 & 0.145 & 0.214 & 0.064 & 0.196 & 0.083 & 0.254 & 0.158 \\
\hline MIN & 0.163 & 0.308 & 0.242 & 0.205 & 0.187 & 0.095 & 0.282 & 0.458 \\
\hline MNF & 0.145 & 0.034 & 0.195 & 0.084 & 0.159 & 0.058 & 0.187 & 0.073 \\
\hline ELE & 0.041 & 0.039 & 0.222 & 0.129 & 0.198 & 0.161 & 0.063 & 0.162 \\
\hline WAT & 0.046 & 0.039 & 0.344 & 0.270 & 0.201 & 0.093 & 0.226 & 0.261 \\
\hline CST & 0.340 & 0.326 & 0.283 & 0.123 & 0.258 & 0.125 & 0.355 & 0.349 \\
\hline TRD & 0.116 & 0.035 & 0.147 & 0.130 & 0.148 & 0.051 & 0.127 & 0.141 \\
\hline TRS & 0.022 & 0.031 & 0.189 & 0.088 & 0.151 & 0.049 & 0.070 & 0.053 \\
\hline HOT & 0.034 & 0.027 & 0.103 & 0.065 & 0.124 & 0.051 & 0.019 & 0.046 \\
\hline INF & 0.048 & 0.036 & 0.251 & 0.118 & 0.183 & 0.072 & 0.130 & 0.089 \\
\hline RLE & 0.502 & 0.727 & 0.213 & 0.177 & 0.210 & 0.173 & 0.554 & 0.776 \\
\hline PRF & 0.074 & 0.050 & 0.384 & 0.256 & 0.242 & 0.119 & 0.230 & 0.216 \\
\hline ADM & 0.024 & 0.020 & 0.254 & 0.118 & 0.127 & 0.052 & 0.168 & 0.090 \\
\hline$S$ & 0.160 & 0.339 & 0.249 & 0.171 & 0.190 & 0.109 & 0.249 & 0.379 \\
\hline$M$ & 0.124 & 0.193 & 0.238 & 0.149 & 0.180 & 0.096 & 0.196 & 0.219 \\
\hline$L$ & 0.097 & 0.203 & 0.212 & 0.187 & 0.177 & 0.111 & 0.138 & 0.295 \\
\hline
\end{tabular}

Note: Note: $\mu$ - mean value, $\delta$ - standard deviation, . - missing data. Source: Author's calculations based on the Banque de France (2012) 
Table 5. Univariate analysis of variance

\begin{tabular}{|c|c|c|c|c|c|c|c|c|}
\hline \multirow{3}{*}{$\begin{array}{c}\text { Grouping } \\
\text { variable }\end{array}$} & \multicolumn{8}{|c|}{ Ratio } \\
\hline & \multicolumn{2}{|l|}{ INV } & \multicolumn{2}{|l|}{ TAR } & \multicolumn{2}{|l|}{ TAP } & \multicolumn{2}{|l|}{ OWC } \\
\hline & $\mathrm{F}$ & $p$ & $\mathrm{~F}$ & $p$ & F & $p$ & $\mathrm{~F}$ & $p$ \\
\hline Country & $F(1.260)=19.94^{*}$ & 0.000 & $F(3.680)=188.6^{*}$ & 0.000 & $F(1.126)=137.6^{*}$ & 0.000 & $F(2.325)=25.52^{*}$ & 0.000 \\
\hline Industry & $F(4.261)=86.16^{*}$ & 0.000 & $F(1.182)=49.58^{*}$ & 0.000 & $F(0.283)=29.35^{*}$ & 0.044 & $F(3.113)=39.54^{*}$ & 0.000 \\
\hline Size & $F(0.973)=14.79^{*}$ & 0.000 & $F(0.308)=10.70^{*}$ & 0.000 & $F(0.035)=3.128^{*}$ & 0.044 & $F(2.231)=23.89^{*}$ & 0.000 \\
\hline Year & $F(0.035)=0.530$ & 0.853 & $F(0.017)=0.572$ & 0.821 & $F(0.020)=1.813$ & 0.061 & $F(0.036)=0.376$ & 0.947 \\
\hline
\end{tabular}

Note: The table presents the results of the one-way ANOVA procedure performed for all of the ratios in the four cross-sections, i.e., across countries, industries, size groups and years. It contains the values of the F-statistic and $p$. Values significant at $p=0,05$ are marked with *. Source: Author's calculations based on the Banque de France (2012)

In the event of finding differences in the ratio means among countries, industries, and (or) size groups, it should be established whether these differences are statistically significant. Then, the analysis of variance (ANOVA) is applicable as a method of studying observations that are dependent on one or more factors acting simultaneously. These factors are also known as grouping or manipulative variables. The analysis of variance (Fisher, 1954) allows us to assess the significance of differences between many means and explains the probability with which the considered factors may be the reason for the discrepancies between the observed group means. If the means differ significantly from each other, it can be intuitively concluded that the analyzed factor affects the dependent variable.

The heterogeneity of the objects from the examined population and some of the similarities found between them imply the need to organize these objects by classifying them according to certain criteria. The idea of classification can be defined as a process of linking objects into categories (called clusters) based on their properties. Therefore, the grouping procedure is the next step of the analysis. One of the many clustering methods that allows us to extract internally coherent groups of objects is $k$-means grouping, which aims at partitioning observations. The partitioning is performed by creating $k$ different, possibly distinct, clusters that are formed by relocating objects among these clusters to minimize the within- group variance while maximizing the between-group variance (Wishart 2003).

The following sets of binominal objects were subject to the $k$-means grouping procedure:

- industries in countries - in individual size groups separately and in all size groups overall,

- size groups in countries - in individual industries separately and in all industries overall,

- size groups in industries - in individual countries separately and in all countries overall.

The advantage of the $k$-means algorithm is the ease of application, even with large data sets. In addition, the target number of clusters must be determined a priori, which can be helpful when that number is based on certain criteria.

\section{Results}

A glance at the descriptive statistics by year, country, industry and size (Table 4) reveals that most ratios are quite stable in time, whereas when the other grouping factors are considered, they are much more varied. Thus, it would be particularly interesting to analyze the population across these three cross-sections.

The one-way ANOVA procedure was conducted in four sections, where the qualitative predictors were country, industry, size and year. The discrimination power of the ratios can be analyzed based on the $F$ statistic and probability $p$ calculated for the entire data set, as presented in Table 5 . 
Table 6. Summary of the cluster analysis results of industries in countries - the number of clusters of a national character (C), industry character (I), and unspecified (C/I)

\begin{tabular}{|c|c|c|c|c|c|c|c|c|c|}
\hline \multirow[t]{2}{*}{ Size group } & \multicolumn{3}{|c|}{9 clusters } & \multicolumn{3}{|c|}{13 clusters } & \multicolumn{2}{|c|}{$\%$ share of clusters } & \multirow[t]{2}{*}{ The dominant effect } \\
\hline & C & I & $\mathrm{C} / \mathrm{I}$ & C & I & $\mathrm{C} / \mathrm{l}$ & C & । & \\
\hline$S$ & 4 & 1 & 4 & 6 & 1 & 6 & $45.5 \%$ & $9.1 \%$ & C \\
\hline M & 4 & 0 & 5 & 9 & 2 & 2 & $59.1 \%$ & $9.1 \%$ & C \\
\hline$L$ & 6 & 0 & 3 & 6 & 1 & 6 & $54.5 \%$ & $4.5 \%$ & C \\
\hline All & 7 & 0 & 2 & 7 & 3 & 3 & $63.6 \%$ & $13.6 \%$ & C \\
\hline
\end{tabular}

Note: The table presents a synthetic summary of the k-means clustering results of binominal objects (industries in countries) in two versions in terms of the number of groups (clusters): for 9 clusters (which corresponds to the number of countries analyzed) and for 13 clusters (corresponding to the number of industries). The procedure was carried out for all size groups overall and for each size group separately, as indicated in the rows. Source: Author's calculations based on Banque de France (2012)

The calculations show that all of the considered ratios are characterized by suitable discriminating abilities across countries, industries and size groups. However, there is no reason to reject the hypothesis regarding equal means of ratios across years, which proves the poor discriminatory power of the diagnostic variables in this section. The results of the analysis of variance across time are important from a methodological perspective because a significant variation in time would mean that it is useful to perform clustering procedures separately for each year. However, the demonstrated lack of significant differences indicates that the time means of variables can be considered typical ratio levels in the analytical period.

To verify whether the country or industry effect is the dominant one, the binominal objects in the form of industries in countries were grouped. If the objects had a tendency to link in a similar way to the national classification, this linking would indicate the superiority of the country effect. The dominance of the industry factors would be indicated by the clustering results in which objects are more similar to each other in a cross-industry section. Usually, in each of the obtained clusters, the dominant item in terms of a country or an industry can be identified. The nature of each cluster was identified as a sectoral or national based on the dominant element in the form of industries or countries. For some clusters, however, it was impossible to determine their nature due to the same or a similar number of repeating national and sectoral items. The inability to identify the dominant element also applies to all of the single-item clusters.

The synthetic summary of the cluster analysis results is presented in Table 6. The analysis was performed for two variants of the number of clusters, the first of which corresponds to the number of countries (9) and the second to the number of industries (13). The detailed results of the $k$-means grouping for all size groups can be found in Appendices A and B.

Based on the above results, it is relatively easy to determine which of the effects, whether country or industry, prevails. Considering the results obtained both in relation to all size groups together and separately, the country specificity is clearly stronger than the industry specificity. The dominant elements in the clusters of a national character are the Netherlands, Poland, Italy and Germany. This country effect dominance is observed in both versions of the cluster number, i.e., when the population is divided into 9 or 13 groups.

Increasing the number of clusters from 9 to 13 does not change the general conclusions regarding the relative importance of the two effects. A more detailed partition, however, leads to a weaker prevalence of the country factors, as demonstrated by a larger share of industry-dominated clusters and, usually, a larger share of unspecified clusters. The industry specificity is exemplified most in the sectors of construction, trade, manufacturing and real estate, which determines the nature of the clusters. 
Table 7. Summary of the cluster analysis results of size groups in countries - the number of clusters of a national character (C), size character (S), and unspecified (C/S)

\begin{tabular}{|c|c|c|c|c|c|c|}
\hline \multirow[t]{2}{*}{ Industry } & \multicolumn{3}{|c|}{ Number of clusters } & \multicolumn{2}{|c|}{$\%$ share of clusters } & \multirow[t]{2}{*}{ The dominant effect } \\
\hline & C & $S$ & $C / S$ & C & S & \\
\hline$A G R$ & 0 & 2 & 7 & $0.0 \%$ & $22.2 \%$ & $S$ \\
\hline MIN & 3 & 1 & 5 & $33.3 \%$ & $11.1 \%$ & C \\
\hline MNF & 5 & 3 & 1 & $55.6 \%$ & $33.3 \%$ & $C$ \\
\hline ELE & 3 & 2 & 4 & $33.3 \%$ & $22.2 \%$ & C \\
\hline WAT & 6 & 1 & 2 & $66.7 \%$ & $11.1 \%$ & C \\
\hline CST & 7 & 1 & 1 & $77.8 \%$ & $11.1 \%$ & C \\
\hline TRD & 3 & 1 & 5 & $33.3 \%$ & $11.1 \%$ & $C$ \\
\hline TRS & 6 & 2 & 1 & $66.7 \%$ & $22.2 \%$ & C \\
\hline НОT & 4 & 2 & 3 & $44.4 \%$ & $22.2 \%$ & C \\
\hline INF & 7 & 1 & 1 & $77.8 \%$ & $11.1 \%$ & C \\
\hline RLE & 5 & 1 & 3 & $55.6 \%$ & $11.1 \%$ & C \\
\hline PRF & 5 & 1 & 3 & $55.6 \%$ & $11.1 \%$ & C \\
\hline ADM & 3 & 2 & 4 & $33.3 \%$ & $22.2 \%$ & C \\
\hline All & 7 & 0 & 2 & $77.8 \%$ & $0.0 \%$ & C \\
\hline
\end{tabular}

Note: The table presents a synthetic summary of the k-means clustering results of binominal objects (size groups in countries), which were grouped into 9 clusters (corresponding to the number of countries analyzed). The procedure was carried out for all industries overall and for each industry separately, as indicated in each row. Source: Author's calculations based on the Banque de France (2012)

To verify the relative importance of the next pair of factors, the country and size effect, the clustering algorithm was performed on binomial objects in the form of size groups in countries. The tendency of these objects to link in a manner similar to the national divisions would indicate the predominance of the country effect. The clustering results, where the partitions coincide more with the size categorization, would thus prove the dominance of the size effect in the corporate WC.

In this analysis, the number of clusters was established as equal to the number of countries covered by the study. Dividing the population into only three groups, which corresponds to the number of size groups, would result in a large number of items in clusters; this, in turn, would make it difficult to identify the actually dominant element in each. In addition, it is likely that the dominant effect in every cluster would be the size effect associated with the occurrence of three variants of the size characteristics and nine variants of the country. The summary of cluster analysis, aimed at comparing the effect of the country and size, is shown in Table 7. The detailed results of the $k$-means grouping for all industries are provided in Appendix C.

Based on the summarized results, it can be concluded that with respect to all industries taken together, the country effect is the dominant one. The factors that determine the national character of the country-domi- 
Table 8. Summary of the cluster analysis results of size groups in industries - the number of clusters of industrial character (I), size character (S), and unspecified (I/S)

\begin{tabular}{|c|c|c|c|c|c|c|}
\hline \multirow{2}{*}{ Country } & \multicolumn{3}{|c|}{ Number of clusters } & \multicolumn{2}{|c|}{$\%$ share of clusters } & \multirow{2}{*}{ The dominant effect } \\
\hline & । & $\mathrm{s}$ & I/S & । & S & \\
\hline AT & 5 & 2 & 6 & $38.5 \%$ & $15.4 \%$ & । \\
\hline $\mathrm{BE}$ & 8 & 1 & 4 & $61.5 \%$ & $7.7 \%$ & । \\
\hline DE & 6 & 3 & 4 & $46.2 \%$ & $23.1 \%$ & । \\
\hline ES & 4 & 6 & 3 & $30.8 \%$ & $46.2 \%$ & S \\
\hline$F R$ & 8 & 2 & 3 & $61.5 \%$ & $15.4 \%$ & 1 \\
\hline IT & 4 & 5 & 4 & $30.8 \%$ & $38.5 \%$ & S \\
\hline $\mathrm{NL}$ & 2 & 4 & 7 & $15.4 \%$ & $30.8 \%$ & $S$ \\
\hline$P L$ & 8 & 3 & 2 & $61.5 \%$ & $23.1 \%$ & 1 \\
\hline PT & 4 & 3 & 6 & $30.8 \%$ & $23.1 \%$ & । \\
\hline All & 7 & 1 & 5 & $53.8 \%$ & $7.7 \%$ & । \\
\hline
\end{tabular}

Note: The table presents a synthetic summary of the k-means clustering results of binominal objects (industries in countries) in two versions in terms of the number of groups (clusters): for 9 clusters (which corresponds to the number of countries analyzed) and for 13 clusters (corresponding to the number of industries). The procedure was carried out for all size groups overall and for each size group separately, as indicated in the rows. Source: Author's calculations based on Banque de France (2012)

nated clusters are primarily Austria and, again, Poland, the Netherlands and Germany, where companies of all sizes create national clusters. The firm specificity related to its size is also more visible in large and small businesses, rather than medium-sized firms. The conclusions regarding the prevalence of the country effect over the size effect refer to all of the industries examined, except agriculture, where the relative importance of the two effects is reversed.

The classification of binomial objects in the form of size groups in industries provides the basis for comparing the impact of the industry effect and the size effect. The advantage of the industry factors would be indicated by a tendency of objects to link in a manner following the industrial classification. The dominance of factors related to the firm size would be accompanied by the clustering results similar to the categorization according to size. The synthetic summary of the clustering results, which aimed to establish the relative importance of the two effects, is shown in Table 8, and the detailed results of the $k$-means grouping procedure for all countries are shown in Appendix D.

Due to the reasons described above, the $k$-means grouping was performed for 13 clusters, which corresponds to the number of industries. Based on the results obtained for all countries, the industry factors must be attributed greater influence on the WC ratios than the factors related to the firm size. The dominant elements in these industry-oriented clusters are primarily the real estate sector, water supply, professional activities, trade and mining. The minority of the size-oriented clusters most often include small or large businesses.

The observed regularity in the relative importance of the industry and size effect for all countries as a total is not the same in each country, separately. The few exceptions to this relatively homogeneous population are Spain, Italy and the Netherlands, where the business sector is less important than the size in terms of the WC. 

When evaluating the relative importance of the country-, industry- and size-specific factors in terms of their impact on the WC of enterprises, it should be remembered that it is barely possible to fully isolate these three effects. Each industry is somehow affected by the characteristics of the country where it operates. Similarly, the broadly defined short-term financing strategy of companies in a given country to some extent also depends on the industrial structure. One can also assume that a similar type of interference, resulting from the overlapping of factors, also occurs in size groups of firms. The industry specificity, similar to the entrepreneurship policy held in different countries, can favor the development of firms of a certain size. Therefore, it would be risky to precisely quantify the extent to which WC management is influenced by each type of factor.

One of the major limitations of this study is the data comparability. Despite the attempts to unify the Banque de France (2012) database, which are part of a broader process of financial reporting harmonization in the European Union, the comparability of the data is still far from perfect. A fully comparable dataset, particularly in terms of time series, would enable more sophisticated data exploration. The range of countries covered by the database is also limited primarily to the old EU members; however, extending the analysis to all EU countries could reveal more useful findings concerning corporate finance.

\section{References}

Appuhami, B. A. R. (2008). The impact of firms' capital expenditure on working capital management: an empirical study across industries in Thailand. International Management Review, 4 (1), 8-21.

Banque de France (2012). Bank for the Accounts of Companies Harmonised - European Sectoral references Database. Available from http://www. bachesd.banque-france.fr

Bancel, F., \& Mittoo, U. R. (2004). Cross-Country Determinants of Capital Structure Choice: A Survey of European Firms. Financial Management, 33 (4), 103-132.

Boillat, P., de Skowronsky, N., \& Tuchschmid, N. (2002). Cluster analysis: application to sector indices and empirical validation. Financial Markets and Portfolio Management, 16 (4), 467-486.
Booth, L., Aivazian, V., Demirgüç-Kunt, A., \& Maksimovic, V. (2001). Capital Structure in Developing Countries. Journal of Finance, 56 (1), 87-130.

Chiou, J., Cheng, L., \& Wu, H. (2006). The determinants of working capital management. The Journal of American Academy of Business, 10 (1), 149-155.

Chittenden, F., Poutziouris, P., \& Michaelas, N. (1998). Financial Management and Working Capital Practices in UK SMEs. Manchester, UK: Manchester Business School.

Cinca, C. S., Molinero, C. M., \& Larraz, J. L. (2005). Country and size effects in financial ratios: A European perspective. Global Finance Journal, 16 (1), 26-47.

Claessens, S., Djankov, S., \& Nenova, T. (2001). Corporate growth and risk around the world. In R. Glick, R. Moreno, \& M. Spiegel (Eds.), Financial Crises in Emerging Markets (pp. 305-338). Cambridge, UK: Cambridge University Press.

Corbett, J., \& Jenkinson, T. (1997). How is investment financed? A study of Germany, Japan, the United Kingdom and the United States. Manchester School, 65, 69-93.

Corbett, J. \& Jenkinson, J. (1996). The Financing of Industry, 1970-1989: An International Comparison. Journal of the Japanese and International Economies, 10 (1), 71-96.

Deloof, M. (2003). Does working capital management affect profitability of Belgian firms? Journal of Business Finance and Accounting, 30 (3-4), 573-588.

Demirgüç-Kunt, A., \& Maksimovic, V.(1999). Institutions, Financial Markets and Firm Debt Maturity. Journal of Financial Economics, 54 (3), 295-336.

Edwards, J., \& Fischer, K. (1994). Banks, Finance and Investment in Germany. Cambridge, UK: Cambridge University Press.

Filbeck, G., \& Krueger, T. (2005). An analysis of working capital management results across industries. Mid-American Journal of Business, 20 (2), 11-18.

Fisher, R. A. (1954). Statistical methods for research workers. Edinburgh, UK: Oliver and Boyd.

Götz, M. (2013). Reflections on the Eurozone's Challenges. Contemporary Economics, 7 (4), 5-24.

Gupta, M. C., \& Huefner, R. J. (1972). A Cluster Analysis Study of Financial Ratios and Industry Characteristics. Journal of Accounting Research, 10 (1), 77-95. 
Hawawini, G., Viallet, C., \& Vora, A. (1986). Industry Influence on Corporate Working Capital Decisions. Sloan Management Review, 27 (4), 15-24.

Helg, R., Manasse, P., Monacelli, T., \& Rovelli, R. (1995). How much (a)symmetry in Europe? Evidence from industrial sectors. European Economic Review, 39 (5), 1017-1041.

Hill, M. D., Kelly, G. W., \& Highfield, M. J. (2010). Net Operating Working Capital Behavior: A First Look. Financial Management, 39 (2), 783-805.

Jõeveer, K. (2013). What Do We Know about the Capital Structure of Small Firms? Small Business Economics, 41 (2), 479-501.

Kieschnick, R., Laplante, M., \& Moussawi, R. (2006). Corporate working capital management: determinants and consequences (Working Paper). The Wharton School.

Kim, Y. H., \& Srinivasan, V. (Ed.). (1991). Advances in working capital management: a research annual. (Vol. 2). Greenwich, CT: EUA Jai Press.

La Porta, R., Lopez-de-Silanes, F., Shleifer, A., \& Vishny, R. (1997). Legal Determinants of External Finance. Journal of Finance, 52 (3), 1131-1150.

Lamberson, M. (1995). Changes in working capital of small firms in relation to changes in economic activity. American Journal of Business, 10 (2), 45-50.

Mayer, C. (1988). New Issues in Corporate Finance. European Economic Review, 32 (5), 1167-1188.

Mayer, C. (1990). Financial Systems, Corporate Finance, and Economic Development. In R. G. Hubbard (Ed.), Asymmetric Information, Corporate Finance, and Investment (pp. 307-332). Chicago, IL: University of Chicago Press.

Mayer, C., \& Alexander, I. (1990). Banks and Securities Markets: Corporate Financing in Germany and the United Kingdom. Journal of the Japanese and International Economies, 4 (4), 450-475.

Misztal, P. (2013). International Trade and Business Cycle Synchronization in Poland, the European Union and the Euro Zone. Contemporary Economics, 7 (3), 65-78.

Mullineux, A., Murinde, V., \& Sensarma, R. (2010). Convergence of Corporate Finance Patterns in Europe. Economic Issues, 15 (2), 49-67.

Murinde, V., Agung, J. A. \& Mullineux, A. W. (2004). Patterns of Corporate Financing and Financial System Convergence in Europe. Review of International Economics, 12 (4), 693-705.
Myers, S. C., \& Majluf, N. (1984). Corporate financing and investment decisions when firms have information that investors do not have. Journal of Financial Economics, 13 (2), 187-221.

Nazir, M. S., \& Afza, T. (2008). On the factor determining working capital requirements. Proceedings of ASBBS, 15 (1), 293-301.

Nunn, K. P. (1981). The strategic determinants of working capital: a product-line perspective. The Journal of Financial Research, 4 (3), 207-219.

Opler, T., Pinkowitz, L., Stulz, R., \& Williamson, R. (1999). The Determinants and Implications of Corporate Cash Holdings. Journal of Financial Economics, 52 (1), 3-46.

Padachi, K. (2006). Trends in Working Capital Management and its Impact on Firms' Performance: An Analysis of Mauritian Small Manufacturing Firms. International Review of Business Research Papers, 2 (2), 45-58.

Palombini, N., Nakamura, W. (2011, April 13). The Determinant Factors of Working Capital Management in the Brazilian Market. Paper presented at the annual meeting of the BALAS Annual Conference, Santiago, Chile.

Petersen, M., \& Rajan, R. (1997). Trade Credit: Theories and Evidence. Review of Financial Studies, 10 (3), 661-691.

Rafuse, M. E. (1996). Working Capital Management: An Urgent Need to Refocus. Journal of Management Decision, 34 (2), 59-63.

Rajan, R. G., \& Zingales, L. (1995). What Do We Know About Capital Structure? Some Evidence from International Data. Journal of Finance, 50 (5), 1421-1460.

Rivaud-Danset, D., Dubocage, E., \& Salais, R. (2001). Comparison Between the Financial Structure of SME Versus Large Enterprise Using the BACH Data Base (Economic Paper No. 155). Economic and Financial Affairs.

Saarani, A. N., \& Shahadan, F. (2012). The Determinant Factors of Working Capital Requirements for Enterprise 50 (E50) Firms in Malaysia: Analysis Using Structural Equation Modelling. Scottish Journal of Arts, Social Sciences and Scientific Studies, 5 (2), 52-66.

Saccurato, F. (1994). The Study of Working Capital. Business Credit, 96 (1), 36-37. 
Sell, C. W. (2005). The Importance of Country versus Sector Characteristics. Managerial Finance, 31 (1), 78-95.

Weinraub, H. J., \& Visscher, S. (1998). Industry Practice relating to Aggressive Conservative Working Capital Policies. Journal of Financial and Strategic Decisions, 11 (2), 11-18.

Wishart, D. (2003). K-Means Clustering with Outlier Detection, Mixed Variables and Missing Values. In M. Schwaiger, O. Opitz (Eds.), Exploratory data analysis in empirical research. Paper presented at The 25th Annual Conference of the Gesellschaft für Klassifikation, University of Munich, Munich 14-16 March, 2001 (pp. 216-226). Berlin: Springer..

\section{Acknowledgements}

The project was funded by the National Centre of Science in Poland on the basis of the decision number DEC-2013/09/B/HS4/01936. 


\section{Appendix A. K-means grouping results for industries in countries (average for all size groups, 9 clusters}

\begin{tabular}{|c|c|c|c|c|c|c|c|c|}
\hline \multicolumn{9}{|c|}{ Cluster number } \\
\hline 1 & 2 & 3 & 4 & 5 & 6 & 7 & 8 & 9 \\
\hline BE_WAT & ES_MIN & BE_MIN & AT_AGR & BE_ELE & DE_CST & AT_RLE & AT_ELE & AT_HOT \\
\hline BE_RLE & ES_CST & BE_CST & AT_MIN & BE_INF & DE_RLE & & AT_WAT & DE_MIN \\
\hline BE_PRF & ES_RLE & BE_ADM & AT_MNF & ES_WAT & & & AT_TRS & DE_MNF \\
\hline IT_AGR & PT_CST & ES_AGR & AT_CST & ES_PRF & & & AT_ADM & DE_ELE \\
\hline IT_MIN & PT_RLE & ES_MNF & AT_TRD & FR_ELE & & & BE_TRS & DE_WAT \\
\hline IT_MNF & & ES_ELE & AT_INF & FR_INF & & & BE_HOT & DE_TRD \\
\hline IT_WAT & & ES_INF & AT_PRF & FR_PRF & & & ES_TRS & DE_TRS \\
\hline IT_CST & & ES_ADM & BE_AGR & IT_ELE & & & ES_HOT & DE_HOT \\
\hline IT_INF & & FR_MIN & BE_MNF & IT_TRS & & & FR_TRS & DE_INF \\
\hline IT_RLE & & FR_WAT & BE_TRD & IT_HOT & & & FR_HOT & DE_PRF \\
\hline IT_PRF & & FR_CST & ES_TRD & IT_ADM & & & PT_ELE & DE_ADM \\
\hline PT_AGR & & FR_ADM & FR_AGR & PT_INF & & & PT_HOT & \\
\hline \multirow[t]{20}{*}{ PT_MIN } & & IT_TRD & FR_MNF & & & & & \\
\hline & & NL_AGR & FR_TRD & & & & & \\
\hline & & NL_MIN & FR_RLE & & & & & \\
\hline & & NL_MNF & PL_AGR & & & & & \\
\hline & & NL_ELE & PL_MIN & & & & & \\
\hline & & NL_WAT & PL_MNF & & & & & \\
\hline & & NL_CST & PL_ELE & & & & & \\
\hline & & NL_TRD & PL_WAT & & & & & \\
\hline & & NL_TRS & PL_CST & & & & & \\
\hline & & NL_HOT & PL_TRD & & & & & \\
\hline & & NL_INF & PL_TRS & & & & & \\
\hline & & NL_PRF & PL_HOT & & & & & \\
\hline & & NL_ADM & PL_RLE & & & & & \\
\hline & & PL_INF & PL_PRF & & & & & \\
\hline & & PL_ADM & PT_TRD & & & & & \\
\hline & & PT_MNF & & & & & & \\
\hline & & PT_WAT & & & & & & \\
\hline & & PT_TRS & & & & & & \\
\hline & & PT_PRF & & & & & & \\
\hline & & PT_ADM & & & & & & \\
\hline
\end{tabular}

Note: The table presents the content of each cluster resulting from the k-means grouping of binominal objects (industries in countries) into 9 clusters (corresponding to the number of countries analyzed) for all size groups overall. The first two letters in each item refer to the country, and the last three letters indicate an industrial sector within this country. Source: Author's calculations based on the Banque de France (2012) 
Appendix B. K-means grouping results for industries in countries (average for all size groups, 13 clusters)

\begin{tabular}{|c|c|c|c|c|c|c|c|c|c|c|c|c|}
\hline \multicolumn{13}{|c|}{ Cluster number } \\
\hline 1 & 2 & 3 & 4 & 5 & 6 & 7 & 8 & 9 & 10 & 11 & 12 & 13 \\
\hline ES_MIN & AT_CST & ES_RLE & ES_ELE & AT_AGR & BE_ADM & BE_ELE & BE_RLE & DE_CST & AT_ELE & AT_RLE & BE_WAT & DE_MIN \\
\hline ES_CST & BE_AGR & PT_RLE & ES_TRS & AT_MIN & ES_WAT & BE_TRS & IT_AGR & DE_RLE & AT_WAT & & BE_PRF & DE_MNF \\
\hline IT_CST & BE_MIN & & ES_INF & AT_MNF & ES_PRF & BE_INF & IT_MNF & & AT_TRS & & IT_WAT & DE_ELE \\
\hline PT_AGR & BE_MNF & & ES_ADM & AT_TRD & FR_PRF & IT_HOT & IT_RLE & & AT_HOT & & & DE_WAT \\
\hline \multirow[t]{19}{*}{ PT_CST } & BE_CST & & FR_MIN & AT_INF & IT_MIN & & PT_MIN & & AT_ADM & & & DE_TRD \\
\hline & ES_AGR & & FR_ELE & AT_PRF & IT_ELE & & & & BE_HOT & & & DE_TRS \\
\hline & ES_MNF & & FR_WAT & BE_TRD & IT_TRS & & & & ES_HOT & & & DE_HOT \\
\hline & FR_AGR & & FR_INF & ES_TRD & IT_INF & & & & FR_TRS & & & DE_INF \\
\hline & FR_MNF & & FR_ADM & FR_TRD & IT_PRF & & & & FR_HOT & & & DE_PRF \\
\hline & FR_CST & & NL_MIN & PL_MIN & IT_ADM & & & & PT_ELE & & & DE_ADM \\
\hline & FR_RLE & & NL_ELE & PL_MNF & PT_WAT & & & & PT_HOT & & & \\
\hline & IT_TRD & & NL_WAT & PL_ELE & PT_PRF & & & & & & & \\
\hline & NL_AGR & & NL_CST & PL_WAT & & & & & & & & \\
\hline & NL_MNF & & NL_TRS & PL_TRD & & & & & & & & \\
\hline & NL_TRD & & NL_HOT & PL_TRS & & & & & & & & \\
\hline & PL_AGR & & NL_INF & PL_HOT & & & & & & & & \\
\hline & PL_CST & & NL_PRF & PL_RLE & & & & & & & & \\
\hline & PT_MNF & & NL_ADM & PL_PRF & & & & & & & & \\
\hline & PT_TRD & & PL_INF & & & & & & & & & \\
\hline & & & PL_ADM & & & & & & & & & \\
\hline & & & PT_TRS & & & & & & & & & \\
\hline & & & PT_INF & & & & & & & & & \\
\hline & & & PT_ADM & & & & & & & & & \\
\hline
\end{tabular}

Note: The table presents the content of each cluster resulting from the k-means grouping of binominal objects (industries in countries) into 13 clusters (corresponding to the number of industries analyzed) for all size groups overall. The first two letters in each item refer to the country, and the last three letters indicate an industrial sector within this country. Source: Author's calculations based on the Banque de France (2012) 
Appendix C. K-means grouping results for size groups in countries (average for all industries)

\begin{tabular}{|c|c|c|c|c|c|c|c|c|}
\hline \multicolumn{9}{|c|}{ Cluster number } \\
\hline 1 & 2 & 3 & 4 & 5 & 6 & 7 & 8 & 9 \\
\hline ES_S & FR_S & PL_S & IT_M & BE_S & AT_S & IT_S & PT_S & DE_S \\
\hline ES_M & FR_M & PL_M & $I_{-} L$ & BE_M & AT_M & & & DE_M \\
\hline ES_L & FR_L & PL_L & & $B E \_L$ & AT_L & & & $D E \_L$ \\
\hline \multirow[t]{4}{*}{ PT_M } & NL_S & & & & & & & \\
\hline & NL_M & & & & & & & \\
\hline & NL_L & & & & & & & \\
\hline & PT_L & & & & & & & \\
\hline
\end{tabular}

Note: The table presents the content of each cluster resulting from the k-means grouping of binominal objects (size groups in countries) into 9 clusters (corresponding to the number of countries analyzed) for all industries overall. The first two letters in each item refer to the country, and the last one indicates the size group within this country. Source: Author's calculations based on the Banque de France (2012)

Appendix D. K-means grouping results for size groups in industries (average for all countries)

\begin{tabular}{|c|c|c|c|c|c|c|c|c|c|c|c|c|}
\hline \multicolumn{13}{|c|}{ Cluster number } \\
\hline 1 & 2 & 3 & 4 & 5 & 6 & 7 & 8 & 9 & 10 & 11 & 12 & 13 \\
\hline MNF_L & CST_L & ADM_S & AGR_M & WAT_S & ELE_M & ADM_L & ELE_S & AGR_S & ELE_L & TRD_L & WAT_L & RLE_S \\
\hline \multirow[t]{5}{*}{ TRD_M } & & ADM_M & AGR_L & WAT_M & TRS_S & & PRF_L & MIN_L & TRS_L & HOT_S & PRF_S & \\
\hline & & & MIN_S & INF_S & TRS_M & & & CST_S & & HOT_M & PRF_M & \\
\hline & & & MIN_M & INF_M & INF_L & & & CST_M & & HOT_L & & \\
\hline & & & MNF_S & & & & & RLE_M & & & & \\
\hline & & & MNF_M & & & & & RLE_L & & & & \\
\hline
\end{tabular}

Note: The table presents the content of each cluster resulting from the k-means grouping of binominal objects (size groups in industries) into 13 clusters (corresponding to the number of industries analyzed) for all countries overall. The first three letters in each item refer to the industry, and the last one indicates the size group within this industry. Source: Author's calculations based on the Banque de France (2012) 
